\title{
Quality of El-Menshawy General Hospital Infrastructure among Nursing Staff
}

\author{
Hanan Mahmoud Elbadry ${ }^{1}$, Samar Hosny Ghadiry ${ }^{2}$, Karima Ahmed El-sayed ${ }^{2}$ \\ ${ }^{1}$ Nursing Administration, Faculty of Nursing \\ ${ }^{2}$ Assist.Prof. of Nursing Services Administration, Faculty of Nursing , Tanta University
}

\section{Abstract}

Background: According to the World Health Organization, every citizen of the world has the right to healthy and safe work; a right to a work environment that enables him or her to live a socially and economically productive life. The hospital infrastructure is the total of all physical, technical and organizational components or assets that are prerequisites for the delivery of health care services. Aim of the study: Assess quality of El-Menshawy General Hospital infrastructure among nursing staff. Research design: Descriptive research design was used in this study. Setting: The study was conducted at El- Menshawy General Hospital departments. Subject: All (530) available nursing staff at the time of data collection .Tools: Tool 1: Nursing staff perception regarding quality of El Menshawy General Hospital infrastructure questionnaire, Tool П:Quality of El-Menshawy General Hospital infrastructure observational checklist. Results: According to them the majority of Nursing staff showed high level of perception regarding neonatal intensive care unit. Also, above fifty percent of nursing staff showed high level of perception regarding emergency room infrastructure, intensive care unit, the facilities and its management, operative room infrastructure, dialysis infrastructure, respectively. According to researcher observation the actual level of quality is high in information technology, neonatal intensive care unit and dialysis infrastructure. Moderate level of quality in technical medical equipment, operative room and facility and its management. While low level of quality in supply facility system. Conclusion: There was significant positive correlation between facility and its management and information technology. Also there was significant positive correlation between disposal system and outreach services. Recommendations: Activation of hospital committee role ( quality committee, health and occupational safety committee, infection control committee and continuous training committee), Provide continuous training program for all nursing staff that improve their performance, increase their knowledge and skills, and motivate them to perform quality patient care.

Key wards: Quality, Infrastructure, Nursing Perception, Nursing staff 


\section{Tanta Scientific Nursing Journal}

\section{Introduction}

Quality was defined as the extent to which health services provided to individuals, patients, and population to improve desired health outcomes. Quality health care is "the right care for the right person at the right time, the first time." The Institute of Medicine has identified six aspects of high-quality care. Health care should be safe, timely, effective, efficient, equitable, and patient-centered. Improved quality outcomes are not, however, delivered by health-service providers alone ${ }^{(1)}$. Healthy work environments have both direct and indirect impacts on patient safety. Healthy work environments have been linked to increased nurse and health care worker retention, recruitment, job satisfaction and have decreased stress and burnout, which subsequently leads to safer patient practices $^{(2)}$.

The term 'infrastructure' is used in manifold ways to describe the structural elements of systems. In the context of a health care system and in reference to health care facilities. The seven major components of the infrastructure of a health care facility include: the facility and its management, the physical infrastructure, the supply facility system, the disposal system, technical medical equipment, information and communication technology, and the outreach services $^{(3)}$.

Facility management covers a wide field of activities related to workplace, facility, support services, property, corporate real estate and infrastructures. There are different classifications proposed by the academic researchers. One classification of facility management scope is premises, support services and information technology. The classification seems to emphasize the facility management function to physical infrastructures rather than to cover all the facility management $\operatorname{activities}^{(4)}$.

Physical Infrastructure refers to structures, systems, and facilities serving the economy of a business, industry, country, city, town, or area, including the services and facilities necessary for its economy to function. It is typically a term to characterize the existence or condition of costly 'technical structures' such as storage chambers, electrical capacity, fuel tanks, cranes, overhead clearances, or components of water supplies, sewers, electrical grids, telecommunications and so forth ${ }^{(5)}$.

Health care waste is defined as the total waste stream from a healthcare establishment, research facilities, laboratories, and emergency relief donations. Health care waste includes 


\section{Tanta Scientific Nursing Journal}

several different waste streams, some of which require more stringent care and disposal including sharps (e.g. needles, razors, scalpels), pathological waste, other potentially infectious waste, pharmaceutical waste, biological waste, and hazardous chemical waste ${ }^{(6)}$.

Medical technology is a broad field where innovation plays a crucial role in sustaining health. Areas like biotechnology, pharmaceuticals, information technology, the development of medical devices and equipment, and more they have all made significant contributions to improving the health of people all around the world ${ }^{(7)}$.Outreach services are used to describe any type of health service that mobilizes health workers to provide services to the population or to other health workers, away from the location where they usually work and live. Outreach services are one of the possibilities to enhance access to health workers and to improve overall retention at country level ${ }^{(8)}$.

\section{Significance of the study}

Nursing staff in healthcare have a legal and moral obligation to ensure a high quality of patient care and to strive to improve care. They are in a prime position to mandate policy, systems, procedures and organizational climates. Accordingly, it is evident that healthcare nursing staff possess an important and obvious role in quality of care and that it is one of the highest priorities of healthcare managers ${ }^{(9)}$. Nursing staff perceive that they are providing high quality nursing care and would recommend that family and friends use the hospital for their health care. To establish this atmosphere there must be assess the quality of infrastructure within hospital ${ }^{(10)}$.

\section{Aim of the study}

\section{The aim of the study is to:-}

Assess quality of El-Menshawy General Hospital infrastructure among nursing staff.

\section{Research question:-}

1-What are the levels of nursing staff perception regarding quality of elMenshawy General Hospital infrastructure?

2-What are the actual levels of quality of el-Menshawy General Hospital?

\section{Materials}

\section{Research design:}

Descriptive research design was used in this study.

\section{Setting:}

The study was carried out at El- Menshawy General Hospital at Gharbia Governorate that is affiliated to Ministry of Health and Population. El Menshawy General Hospital consists of three building and contains 20 units with 258 beds. 
Tools: Tool 1: Nursing staff perception regarding quality of El Menshawy General Hospital infrastructure questionnaire.

Tool П:Quality of El-Menshawy General Hospital infrastructure observational checklist.

\section{Methods}

1. Official permission was obtained from El Menshawy General Hospital to obtain the approval and assistance to collect the data.

2. Ethical consideration: Nursing staff consent was obtained from the participation after exploration of the nature and purpose of the study confidentiality of the information's obtained from and the right to withdrawal is preserved.

4. The questionnaire sheets were submitted to five experts for testing the content and face validity.

6. Reliability of tool was tested using Crombachs Alpha Coefficient Test, its value $=0.899$.

7. Pilot study was carried out after the expert's opinion and before starting the actual data collection. The aim of pilot study was to test the sequence of items, clarity, applicability, and relevance of questions. Pilot study also served to estimate the time required for filling the questionnaire sheet. The estimated time needed to complete the questionnaire items from nursing staff were 10-15 minutes . It was carried out on a sample $10 \%(n=53)$ of nursing staff .These sample was excluded from the main study sample during the actual collection of data. Necessary modification was done.

8. Data collection phase: The data was collected from the identified subject by the researcher. The researcher met the nursing staff in small groups during their work shifts to distribute the questionnaire. The nursing staff recorded the answers in presence of the researcher to ascertain that all questions were answered. 


\section{Results}

Table (1)Personal characteristics of nursing staff $(n=530)$

\begin{tabular}{|c|c|c|}
\hline Variables & $\overline{\mathbf{N}}$ & $\%$ \\
\hline \multicolumn{3}{|l|}{ Age } \\
\hline$>30$ years & 216 & 40.75 \\
\hline $30->40$ years & 270 & 50.94 \\
\hline$<40$ years & 44 & 8.30 \\
\hline Range & \multicolumn{2}{|c|}{$22-46$} \\
\hline Mean \pm SD & \multicolumn{2}{|c|}{$31.928 \pm 5.757$} \\
\hline \multicolumn{3}{|l|}{ Level of education } \\
\hline Nursing diploma & 42 & 7.92 \\
\hline Nursing technical & 185 & 34.91 \\
\hline Bachelor of nursing & 303 & $\mathbf{5 7 . 1 7}$ \\
\hline \multicolumn{3}{|l|}{ Years of experiences } \\
\hline$>5$ years & 70 & 13.21 \\
\hline $5->10$ years & 231 & 43.58 \\
\hline$<10$ years & 229 & 43.21 \\
\hline Range & \multicolumn{2}{|c|}{$1-26$} \\
\hline Mean \pm SD & \multicolumn{2}{|c|}{$11.253 \pm 6.044$} \\
\hline \multicolumn{3}{|l|}{ Unit of work } \\
\hline ICU Infrastructure(intensive care unit) & 112 & 21.13 \\
\hline ER Infrastructure(emergency room) & 108 & 20.38 \\
\hline Dialysis Infrastructure & 99 & 18.68 \\
\hline NICU Infrastructure(neonatal intensive care unit) & 120 & 22.64 \\
\hline OR Infrastructure(operative room) & 91 & $\mathbf{1 7 . 1 7}$ \\
\hline \multicolumn{3}{|l|}{ Training courses related to quality } \\
\hline Yes & 208 & 39.25 \\
\hline No & 322 & 60.75 \\
\hline \multicolumn{3}{|l|}{ Graduation title } \\
\hline Supervisor nurse & 329 & 62.08 \\
\hline Staff nurse & 201 & 37.92 \\
\hline
\end{tabular}

Table (1): illustrates personal characteristics of nursing staff such as : age, educational level ,years of experiences, , unit of work, previous training courses and job title. The age of nurses ranged from 22- 46 years old with mean age $31.94 \pm 5.77$. More than half $(57,17 \%)$ of nursing staff had Bacalerote in nursing, while 7,9\% of nursing staff had Nursing Diploma in the nursing profession. About 43,58\% of nursing staff had an experience between 5-10 years in nursing profession. While $(13,21 \%)$ of them had an experience less than 5 years in the working area respectively. Nearly one quarter $(22,6 \%)$ of nursing staff are working at neonatal Intensive Care Unit and $(21,1 \%)$ of them are working at intensive care unit. About $(39,4 \%)$ of all nurses had previously course on quality. About $(62,1 \%)$ of nursing staff are supervisor nurse according to graduation title, while $(37,9 \%)$ are staff nurse, respectively. 


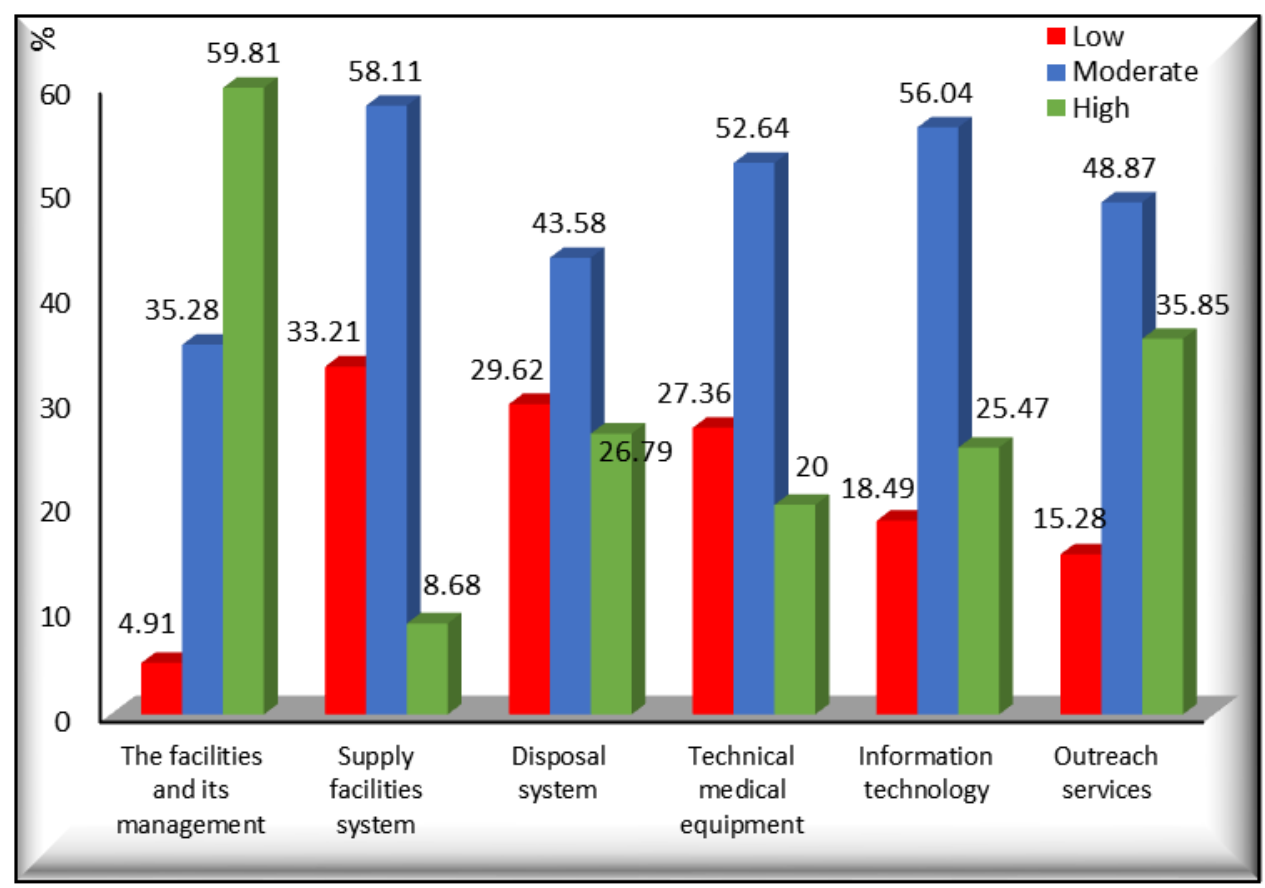

Figure (1): Levels of nursing staff perception regarding hospital infrastructure quality

$$
(\mathbf{n}=\mathbf{5 3 0})
$$

Figure (1)reveals levels of nursing staff perception regarding hospital infrastructure quality. Above fifty percent $(58,11 \%, 56,04 \%, 52,64 \%)$ of nursing staff had moderate level of perception regarding supply facility system, information technology and technical medical equipment, respectively. About 59,81\% , 35,85\% of the nursing staff had high level of perception regarding the facility and its management and outreach services, respectively .About $33,21 \%, 29,62 \%, 27,36 \%$ of the nursing staff had low level of perception regarding supply facility system, disposal system and technical medical equipment, respectively. 


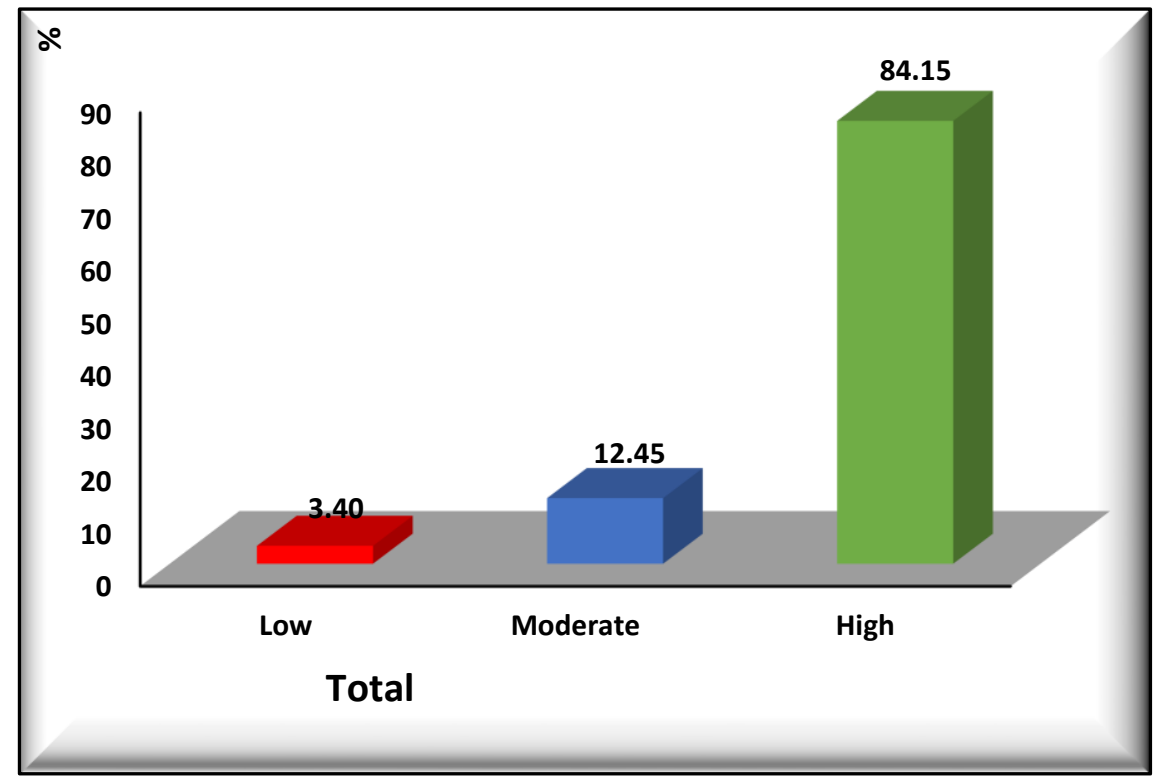

Figure (2): Levels of nursing staff perception regarding hospital infrastructure quality $(\mathbf{n}=\mathbf{5 3 0})$

Figure (2)reveals levels of nursing staff perception regarding hospital infrastructure quality. The majority $(84,15 \%)$ of nursing staff had high level of perception. While $(12,45 \%)$ of the nursing staff had moderate level of perception . On the other hand, $(3,40 \%)$ of the nursing staff had low level of perception regarding hospital infrastructure quality. 
Tanta Scientific Nursing Journal

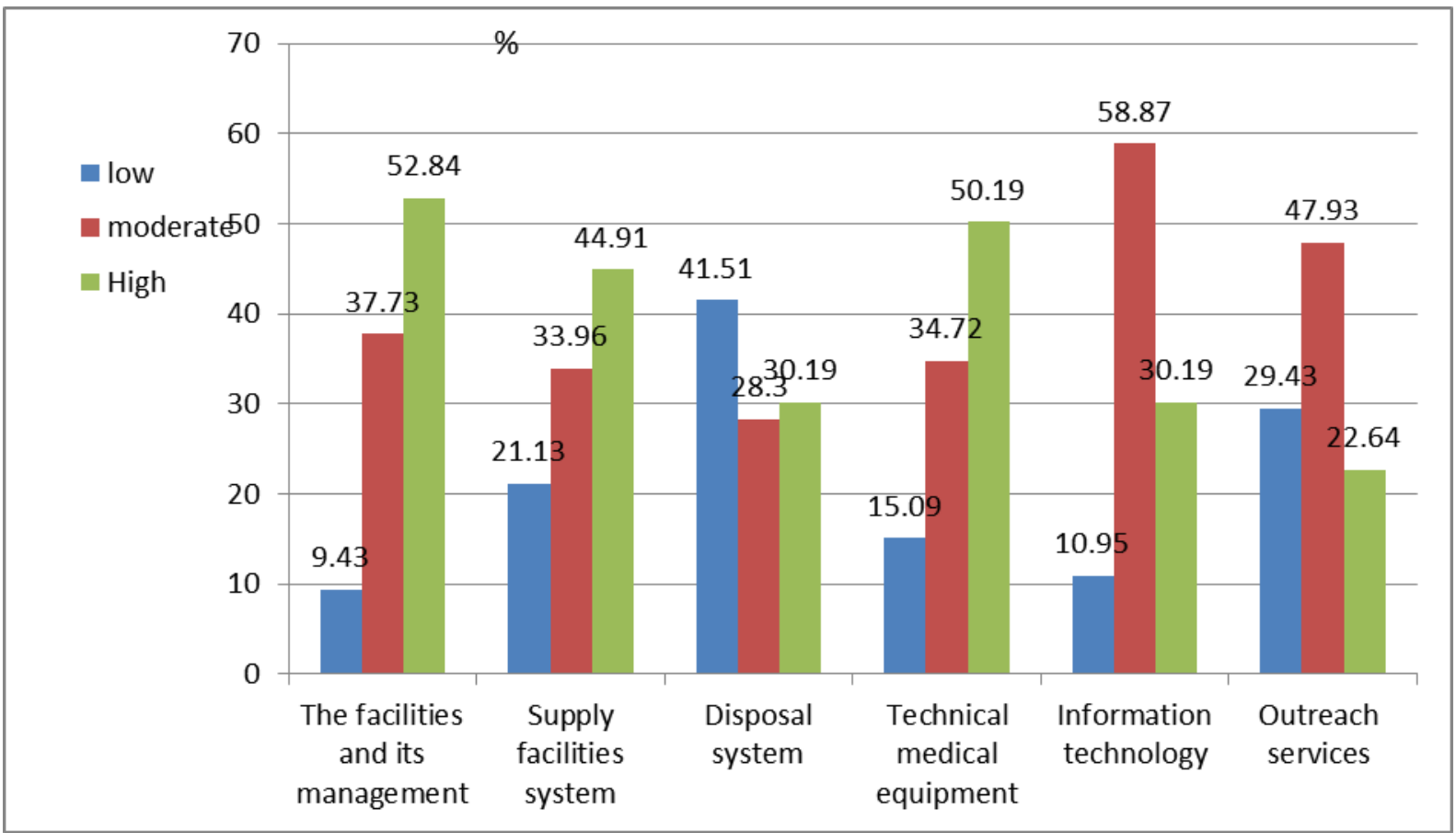

Figure (3): Actual level of quality of EI Menshawy General Hospital according to researcher observation $(\mathbf{n}=\mathbf{5 3 0})$

Figure (3): reveals actual level of quality of El Menshawy General Hospital according to researcher observation. The actual level of quality in information technology is high $(58,87 \%)$ and above (50\%) in technical medical equipment and the facilities and its management. The quality of supply facility system is $(21 \%)$, respectively. 


\section{Tanta Scientific Nursing Journal}

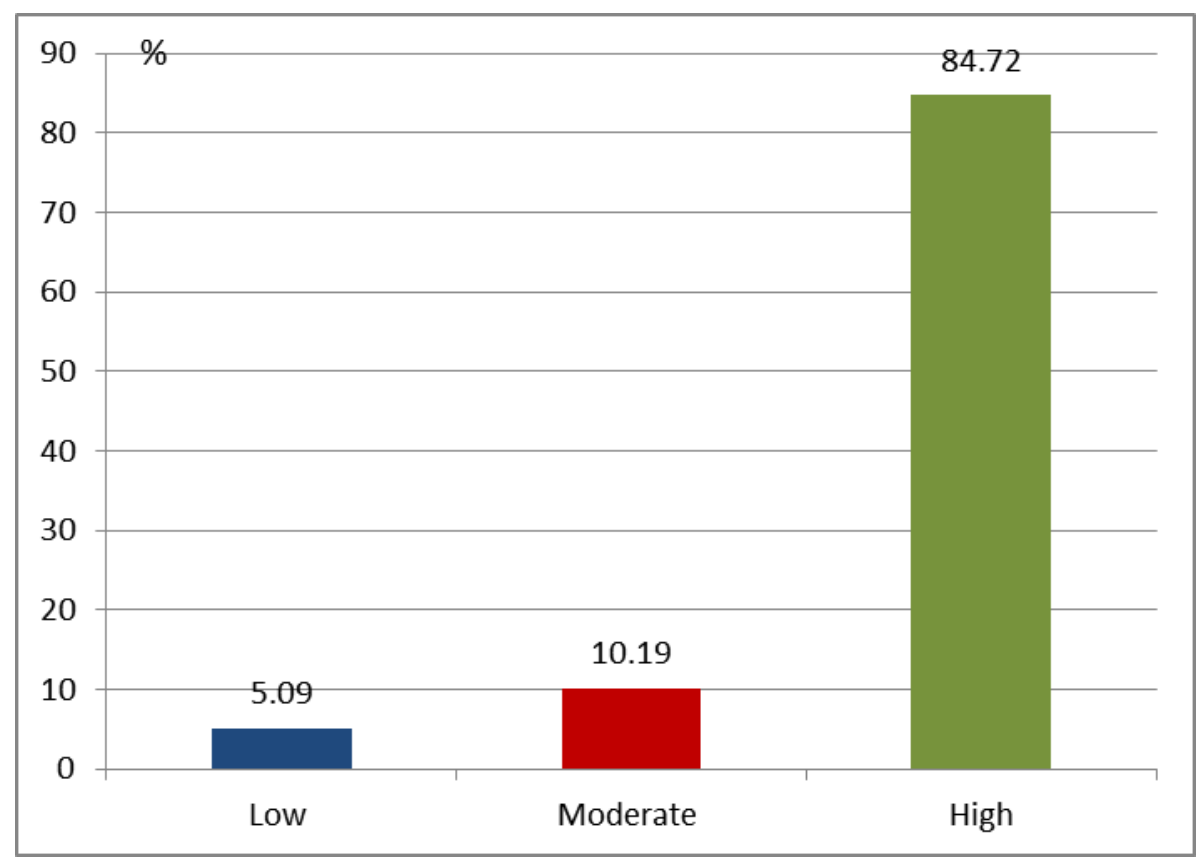

Figure (4): Actual level of quality of El menshawy general hospital according to researcher observation $(n=530)$

Figure (4): reveals actual level of quality of El menshawy general hospital according to researcher observation. The level of quality was high in about $(84,72 \%)$. While moderate level of quality was about $(10.19 \%)$. On the other hand low level of quality is about $(5,09 \%)$ regarding the hospital infrastructure quality. 


\section{Tanta Scientific Nursing Journal}

Table (2) Correlation between nursing staff perception and researcher observation regarding hospital infrastructure quality related to quality dimensions $(n=530)$

\begin{tabular}{|c|c|c|c|c|c|c|}
\hline \multicolumn{2}{|c|}{ Quality dimensions } & $\begin{array}{l}\text { The facilities } \\
\text { and its }\end{array}$ & $\begin{array}{l}\text { Supply } \\
\text { facilities }\end{array}$ & $\begin{array}{c}\text { Disposal } \\
\text { system }\end{array}$ & $\begin{array}{l}\text { Technical } \\
\text { medical }\end{array}$ & $\begin{array}{l}\text { Information } \\
\text { technology }\end{array}$ \\
\hline \multirow{2}{*}{$\begin{array}{c}\text { Supply facilities } \\
\text { system }\end{array}$} & $\mathbf{R}$ & 0.487 & & & & \\
\hline & P-value & $<0.001 *$ & & & & \\
\hline \multirow{2}{*}{ Disposal system } & $\mathbf{R}$ & 0.479 & 0.441 & & & \\
\hline & P-value & $<0.001 *$ & $<0.001 *$ & & & \\
\hline \multirow{2}{*}{$\begin{array}{l}\text { Technical } \\
\text { medical } \\
\text { equipment }\end{array}$} & $\mathbf{R}$ & 0.366 & 0.526 & 0.501 & & \\
\hline & P-value & $<0.001 *$ & $<0.001 *$ & $<0.001 *$ & & \\
\hline \multirow{2}{*}{$\begin{array}{l}\text { Information } \\
\text { technology }\end{array}$} & $\mathbf{R}$ & 0.260 & 0.322 & 0.354 & 0.421 & \\
\hline & P-value & $<0.001 *$ & $<0.001 *$ & $<0.001 *$ & $<0.001 *$ & \\
\hline \multirow{2}{*}{ Outreach services } & $\mathbf{R}$ & 0.212 & 0.225 & 0.155 & 0.355 & 0.283 \\
\hline & P-value & $<0.001 *$ & $<0.001 *$ & $<0.001 *$ & $<0.001 *$ & $<0.001 *$ \\
\hline
\end{tabular}

Table (2) illustrate correlation between nursing perception regarding hospital infrastructure quality related to quality dimensions. There was a significant positive correlation between the facility and its management and information technology $(\mathrm{P}=0.001)$. Also there was significant positive correlation between nursing staff perception and researcher observation regarding hospital infrastructure quality. 


\section{Tanta Scientific Nursing Journal}

\section{Discussion}

The concept of infrastructure is an indirect measure quality of care ${ }^{(11)}$. Infrastructure includes the tangible features of a service delivery, which is related to equipment, furniture, physical appearance of the hospital, facilities, availability of resources, and environment ${ }^{(12)}$. It is also referred to as manmade organization's physical facility or services which include interior attributes such as design, layout, and equipment ${ }^{(13-14)}$.

According to personal characteristics the finding of the present study revealed that the minority of total nursing staff (figure 5) received training courses related to quality, this could be due to training initiatives are not always prioritized by hospital administration. Supervisor nurse more than half of total nursing staff, and it is generally believed that more experienced nurse provide higher quality, efficient care (Table, 1).Coyle et al.,(2012) ${ }^{(15)}$ and Buckley et al., (2010)(16) ${ }^{(16}$ sugested that training courses related to quality is associated with improvements in clinical outcomes and direct benefits for service users or care systems.

\section{Levels of nursing perception regarding} hospital infrastructure quality

In the present study offer that more than eighty percent of the nursing staff in relation to quality of hospital infrastructure specifically in perception regarding neonatal intensive care unit infrastructure this may due to more experienced supervise nurse and continuous training and supervise the nursing staff about neonatal intensive care unit standards and making training courses for nursing staff. While, more than fifty percent in perception regarding emergency room, intensive care unit, operative room, dialysis Infrastructure and the facilities and its management and these from nursing staff opinions, this could due to the more specialized departments require high qualified nursing staff and had more training courses. But less than fifty percent of the studied nurses in relation to perception regarding the disposal system, technical medical equipment, information technology, and outreach services this could be due to lack of specialized reviewing committee for these departments about following the quality standards in introducing the patient care and lack of training courses according to quality standards .

\section{Actual level of quality of El- Menshawy}

\section{General Hospital}

According to researcher observation According to researcher observation, The level of quality is high in neonatal intensive care unit infrastructure and this also may due to well trained supervise 


\section{Tanta Scientific Nursing Journal}

nurse which reflect on the nursing staff skills about neonatal intensive care unit standards and making training courses for nursing staff. The level of quality in dialysis infrastructure was high, this may be due to more daily supervision and continuous on job training . Moderate level of quality is in information technology. Regarding low level of quality infrastructure founded in disposal system and emergency room infrastructure, this may be due to lack of continuous supervision and the nursing staff not aware about quality standard implementation .

Oliver S, Morse J (2015) ${ }^{(17)}$ show that nurses often function as the 'protector' in the NICU aiming to prevent additional stress to the infant and families. Neonatal nurses recognize the importance of quality standard in the NICU, which has allowed for successful advanced medical interventions, including the use of surfactant and continuous positive airway pressure. However, nurses are responsible for many facets of care in the NICU .

Finally, the findings of the study suggest that inadequacies in hospital infrastructure limit access to health care and contribute to poor quality of care outcomes. It can be seen as a major component of the structural quality of a health care system. The built environment dimension is determined by the interplay of four features: accessibility; constructability; functionality; and materials ${ }^{(18)}$.

In a comprehensive literature review conducted by Ulrich et al. (2008) ${ }^{(19)}$, the authors found evidence that the quality of the aesthetic aspects of the physical design (e.g. ward layout, window view, floor and furniture coverings, ventilation and water supply systems) not only influences the quality of clinical spaces (e.g. air quality; cleanliness of floors, walls, furniture, etc.) but has also an impact on clinician's behaviors, thus impacting on the clinical quality of care provided and care outcomes (e.g. hospital-acquired infections, patient falls, length of stay).

Evidence based design is a current trend in facility infrastructure where relevant and proven design innovations that optimize patient safety, quality of care and satisfaction as well as work place safety ${ }^{(20)}$.

\section{Conclusion}

The majority of nursing staff showed high level of perception regarding neonatal intensive care unit infrastructure. Also, above fifty percent of the nursing staff showed high level of perception regarding emergency room infrastructure, Intensive Care Unit infrastructure, the facilities and its management, operative room infrastructure, dialysis infrastructure. About less than fifty percent of nursing staff showed moderate level of perception 
regarding supply facility system and information technology . According to researcher observation the actual level of quality is high in information technology, neonatal intensive care unit and dialysis infrastructure. Moderate level of quality in technical medical equipment, operative room and facility and its management. While low level of quality in supply facility system and emergency room infrastructure.

\section{Recommendations}

\section{At the nursing staff:}

- Increase the nursing awareness about the importance of implementation of quality standards that lead to quality and low cost services.

- Provide continuous training program for all nursing staff that improve their performance, increase their knowledge and skills, and motivate them to perform quality patient care.

- Nursing supervisor need to be aware of infrastructure quality standards and its impact on quality of patient care.

- Activation of hospital committee role ( quality committee, health and occupational safety committee, infection control committee and continuous training committee).

\section{References}

1. Institute of Medicine (2015). Keeping patients safe: transforming the work environment of nurses. Washington, DC: National Academy Press.

\section{Spence Laschinger HK, Finegan} J, Wilk P(2011) . Situational and dispositional influences on nurses' workplace well-being: the role of empowering unit leadership. Nurse Res. 60(2):124-31.

3. , Ngoli B (2015).Rapid assessment of infrastructure of primary health care facilities a relevant instrument for health care systems management.BMC Healt h Services Res. 15:183.

4. Stichler JF.(2012) Creating a healthy, positive work environment: A leadership imperative. Nursing for Women's Health, 13(4): 341-346.

5. Das RC.(2017) Handbook of Research on Economic, Financial, and Industrial Impacts on Infrastructure Development. Advances in Finance, Accounting, and Economics IGI Global.

6. Imdad S, Anwar S, Shoukat MS (2013) .Healthcare Waste: Evaluation of its Generation Rate and Management Practices in Tertiary Care Hospitals of Lahore. Annals. 19 (4): $2013 ; 274-81$.

7. Mitchell PH, Heinrich J, Moritz P, et al(2013). Outcome measures and care delivery systems: Introduction and 
purposes of the conference. Medical Care. 35(1 1):NSl-5.

8. National Quality Forum.(2014) National consensus standards for nursing- sensitive care: an initial performance measure set. Washington, DC: National Quality Forum; 2014.

9. Parand A, Dopson S, Renz A,(2014).The role of hospital managers in quality and patient safety: a systematic review. BMJ Open. 4(9):e005055.

10. Purdy N, Laschinger HK,(2010) .Olivera: Effects of work environments on nurse and patient outcomes. Journal of Nursing Management, 18, 901-913.

11. Jooyeon H and Soocheong J. (2012): The effects of dining atmospherics on behavioral intentions through quality perception", Journal of Service Marketing 1(26): 262-272.

12. Zeithaml A, Bitner J. \&Gremler D. (2015). Services marketing: integrating customer focus across the firm. $5^{\text {th }}$ ed. New York.

13. Chassin M, LoebJ.(2011)The Ongoing Quality Improvement Journey: Next Stop, High Reliability. Health Affairs. 30 (4): 559-68.

14. IslamF,Halim A, Rahman A, Dalal $\mathbf{K}(\mathbf{2 0 1 5})$. Assessment of quality of infrastructure and clinical care performance of HCPs during $\mathrm{MNH}$ services at district and sub-district level government hospitals, Bangladesh. Health MED. (12): 500-10.

15. Coyle YM, Mercer SQ, MurphyCullen CL et al(2012). Effectiveness of a graduate medical education program for improving medical event reporting attitude and behaviour. Quality and Safety in HealthCare 14:383-388

16. Buckley JD, Joyce B, Garcia AJ etal (2010).Linking residency training effectiveness to clinical outcomes: a quality improvement approach. 36 (5):203-208

17. Oliver $\quad$ S, Morse $\quad \mathbf{J}(\mathbf{2 0 1 5})$ Developmental care and quality assessment program at Scott and White Memorial Hospital .

18. Enoch M.(2016) Sustainable transport, mobility management and travel plans. Routledge .

19. Ulrich S, Zimring C, Zhu X, Du Bose $\mathbf{J}(2013)$ A. A review of the research literature on evidence-based healthcare design. HERD: Health Environments Research \& Design Journal. 61-125.

20. Stantec Consulting Ltd. (2016) Advanced Hospital Design: Roadmap for the Development of a Sustainable Hospital Complex. 